\title{
Analisa Dan Optimasi Recovery Perolehan Cadangan Gas Dengan Melihat Parameter Design Sumur Pada Struktur Musi Barat Di Lapangan Riyadh
}

\author{
Rycha Melysa $^{1}$, Agus Masduki $^{2}$, Idham Khalid ${ }^{3}$ \\ ${ }^{1}$ Jurusan Teknik Perminyakan Universitas Islam Riau
}

\begin{abstract}
Abstrak
Lapangan Riyadh merupakan lapangan yang memiliki potensi cadangan gas. Berdasarkan hasil perkiraan cadangan secara volumetric lapangan Riyadh memiliki cadangan sebesar 686.334 Bcf. Lapangan Riyadh ini memiliki 28 sumur yaitu hanya 20 sumur yang berproduksi hingga tahun 2016. Perolehan gas pada lapangan Riyadh hingga akhir tahun 2016 yaitu sebesar 505.336 Bcf. Maka perlu dilakukan perkiraan cadangan berdasarkan material balance dan melakukan optimasi recovery perolehan gas sesuai dengan design sumur di lapangan riyadh. Pada lapangan Riyadh ini dilakukan analisa forecast tekanan terhadap kumulatif produksi gas untuk mengetahui tekanan pada kumulatif produksi gas terhadap waktu. Selanjutnya dilakukan perhitungan perkiraan cadangan dengan metode plot $\mathrm{P} / \mathrm{z}$ vs Gp dan dilakukan identifikasi driving mechanism. Dari hasil perkiraan cadangan dapat dihitung perkiraan recovery factor current dan recovery factor predict . tahap optimasi recovery perolehan gas dilakukan dengan prosper dan mbal software.

Hasil perkiraan cadangan gas dengan material balance plot P/z vs Gp sebesar 702.895 Bcf. Analisa plot P/z vs Gp dapat diketahui bahwa reservoir pada lapangan Riyadh dipengaruhi aquifer influx sehingga dapat di indikasi dari hasil metode cole plot, driving mechanism lapangan Riyadh ini adalah strong water drive .kemudian dari hasil perhitungan cadangan plot P/z vs Gp untuk RF current sebesar $72 \%$ dengan RF prediksi $82 \%$ berdasarkan manual. Setelah dilakukan simulasi Mbal recovery perolehan gas pada lapangan Riyadh dapat di optimasi sampai $85 \%$ berdasarkan parameter design sumur yaitu tubing 3 inch.
\end{abstract}

Kata-Kata kunci: Recovery, reserves, driving mechanism

Koresponden Penulis : richamelysa@eng.uir.ac.id

\begin{abstract}
Abstrack
Riyadh field is a field with potential gas reserves. Based on the results of volumetric reserves in the Riyadh field it has a reserve of 686,334 Bcf. The Riyadh field has 28 wells, with only 20 wells producing by 2016, the gas gains in Riyadh 2016 amounted to 505,336 Bcf. Furthermore, it needs to be done to make improvements of forecasting reserve by using the material balance and optimization of gas recovery that suitable with the well design in the Riyadh field. In the Riyadh field, forecast analysis of the pressure on the cumulative production of gas to determine the pressure on the cumulative gas production over time. Furthermore, the calculation of reserve estimates by plot method P / z vs Gp and identification of driving mechanism from the estimates of reserves can be calculated estimates of recovery factor current and recovery factor predict the recovery gas recovery optimization step is performed with prosper and mbal software.

The result of gas reserve estimation with material plot balance of P / z vs. Gp is 702,895 Bcf. Analysis plot P / z vs. Gp can be seen that the reservoir on the field Riyadh influenced aquifer influx so that it can be in indication of the results of Cole plot method, driving mechanism Riyadh field is strong water drive. Then from the calculation of plot calculation $\mathrm{P}$ / z vs Gp for RF current of $72 \%$ with RF prediction $82 \%$ based on manual. After simulation Mbal recovery of gas recovery in Riyadh field can be optimized up to $85 \%$ based on well design parameter that is 3 inch tubing.
\end{abstract}

Key words: Recovery, reserves, driving mechanism

Corresponding Author : richamelysa@eng.uir.ac.id

\section{PENDAHULUAN}

Gas merupakan salah satu energy yang saat ini dikembangkan. Untuk mendapatkan energy ini perlu dilakukan tahap yang disebut dengan explorasi. Kegiatan explorasi ini adalah kegiatan tahap pencarian energy bumi yaitu dengan melakukan interpretasi geologi sehinga menghasilkan data yang dapat dilakukan perkiraan cadangan. Perkiraan cadangan merupakan proses kuantifikasi formal suatu endapan hidrokarbon (Gas).

Pada dasarnya prinsip perhitungan cadangan berdasarkan hasil suatu perkiraan. Adapun metode perkiraan cadangan gas yaitu salah satunya adalah metode material balance Plot $\mathrm{P} / \mathrm{z}$ vs Gp. Metode ini dilakukan perhitungan perkiraan cadangan berdasarkan sejarah tekanan dan sejarah produksi. Metode material balance 
Plot $\mathrm{P} / \mathrm{z}$ vs Gp dan mengoptimasi recovery perolehan gas dengan melihat parameter design sumur lapangan Riyadh dan melakukan analisa untuk manifold pressure yang sesuai agar setiap sumur dapat berproduksi dengan baik tanpa ada kehilangan produksi.

Perhitungan perkiraan cadangan dapat dilakukan dengan berbagai metode. Seiring perkembangan teknologi, maka metode perhitungan cadangan hingga dengan pengembangan dapat dilakukan dengan menggunakan software seperti Simulator IPM, Mbal dan Prosper, tanpa mengubah filosofi perhitungannya.

\section{METODOLOGI}

Metodologi penelitian ini adalah menganalisis data cadangan gas, diving mechanism dan optimasi dari lapangan dengan pendekatan matematis dan software Simulator IPM, Mbal dan Prosper.

\section{TEORI DASAR}

\section{Cadangan Gas}

\section{material balance}

Prinsip kekekalan massa yang dapat digunakan untuk reservoir gas, menyatakan hubungan material balance, sebagai berikut :

"Massa gas terproduksi = Massa semula di reservoir - massa sisa di reservoir."

Persamaan material balance untuk term standard cuft, adalah :

SCF yang diproduksi $=$ SCF semula + SCF sisa

Material balance dalam term mole gasnya, sebagai berikut :

$$
\mathrm{n}_{\mathrm{p}}=\mathrm{n}_{\mathrm{i}}-\mathrm{n}_{\mathrm{f}}
$$

Dimana $\mathrm{p}, \mathrm{i}$, dan $\mathrm{f}$ menunjukkan yang diproduksi, mula-mula, dan akhir.Bila Vi adalah volume pori gas semula dalam cuft, dan Pf adalah tekanan akhirnya, We adalah cuft air yang masuk ke dalam reservoir, maka volume akhir (Vf) dalam bentuk satuan SCF.

$$
\mathrm{Vf}=\mathrm{Vi}-(\mathrm{We}+\mathrm{Bw} \mathrm{Wp})
$$

$\mathrm{Vf}, \mathrm{Vi}, \mathrm{We}$, dan $\mathrm{WpBw}$ dalam reservoir barrel, Bw adalah faktor volume formasi air dalam reservoir barrel per stock tank barrel. Dari hukum gas didapat :

$$
n=\frac{P V}{z R T}, \text { maka } n_{p}=\frac{p_{b} G b}{z_{b} R T_{b}} ; n_{i}=5,615 \frac{p_{i} V_{i}}{z_{i} R T}
$$

Dan

$$
n=5,615 \frac{p_{i} V_{i}}{z_{i} R T}=5,615 \frac{P(V i-W e+W p B w)}{z R T}
$$

keterangan :

$$
\begin{array}{ll}
\mathrm{Gp} & =\text { Kumulatif produksi gas dari Pi ke } \mathrm{P}, \text { scf. } \\
\mathrm{R} & =\text { Konstanta gas, } 10.732 \text { cuft-psi/lbmol- }{ }^{\circ} \mathrm{R} . \\
\mathrm{T} & =\text { Temperatur reservoir }\left(460+{ }^{\circ} \mathrm{F}\right),{ }^{\circ} \mathrm{R}
\end{array}
$$

Dengan demikian, Vi dalam term G (scf gas mula-mula) dan subtitusi Bgi dan Bg pada tekanan Pi dan P menjadi :

$$
G p=\frac{G(B g-B g i)+W e-W p B w}{B g}
$$


Untuk Reservoir tanpa water influx dan Produksi air persamaan menjadi :

$$
\begin{gathered}
\mathrm{Gp}=5.615 \frac{\mathrm{Z}_{\mathrm{b}} \mathrm{T}_{\mathrm{b}}}{\mathrm{P}_{\mathrm{b}} \mathrm{T}}\left[\frac{\mathrm{Pi}}{\mathrm{Zi}}-\frac{\mathrm{P}}{\mathrm{Z}}\right] \\
\mathrm{Gp}=\frac{\mathrm{G}(\mathrm{Bg}-\mathrm{Bgi})}{\mathrm{Bg}} \\
\mathrm{G}=\frac{\mathrm{GpBg}}{\mathrm{Bg}-\mathrm{Bgi}}
\end{gathered}
$$

keterangan :

$\mathrm{Gp}=$ Kumulatif produksi gas dari Pi keP, scf.

$\mathrm{z}_{\mathrm{b}}=$ Gas deviation factor pada kondisi standar.

$\mathrm{Z}_{\mathrm{i}}=$ Gas deviation factor pada mula-mula.

$\mathrm{z}=$ Gas deviation factor pada reservoir.

$\mathrm{T}_{\mathrm{b}}=$ Temperatur standar, ${ }^{\circ} \mathrm{R}$.

$\mathrm{T}=$ Temperatur reservoir, ${ }^{\circ} \mathrm{R}$.

$\mathrm{p}_{\mathrm{b}}=$ Tekanan pada kondisi standar, psia.

$\mathrm{p}_{\mathrm{i}}=$ Tekanan mula-mula, psia.

$\mathrm{p}=$ Tekanan reservoir, psia.

$\mathrm{We}=$ water influx (encroachment $)$ kumulatif dari Pi menuju P, STB

$\mathrm{Wp}=$ produksi air kumulatif dari pi menuju $\mathrm{p}, \mathrm{STB}$

Metode pertama untuk untuk mendeskripsikan water drive mechanism adalah analisa data produksi dari sumur-sumur yang dibor pada bagian bawah struktur atau dari analisa log atau analisa DST (Drill Stem test) dari sumur-sumur yang dibor pada bagian bawah struktur setelah sejumlah gas telah diproduksikan dan beberapa kenaikan batas kontak gas-air.

Metode kedua untuk memperkirakan water influx adalah dengan menyusun kembali persamaan material balance dan menentukan besarnya kombinasi jumlah gas mula-mula didalam reservoir ditambah water influx kumulatif pada beberapa waktu yang berbeda. Jumlah gas mula-mula di dalam reservoir adalah konstan terhadap waktu atau jumlah yang diproduksikan, sehingga plot $\mathrm{G}$ versus $\mathrm{Gp}$ harus merupakan garis horizontal.

$$
\mathrm{G}=\frac{\mathrm{GpBg}}{\mathrm{Bg}-\mathrm{Bgi}}
$$

Persamaan diatas digunakan untuk menghitung $\mathrm{G}$ pada suatu reservoir dimana terdapat water influx, harga $\mathrm{G}$ yang dihitung akan terus bertambah sebagaimana Gp bertambah.

Hal ini disebabkan persamaan material balance yang digunakan tidak benar. $G$ yang dihitung sebenarnya adalah $\mathrm{G}+\mathrm{f}(\mathrm{we})$, dimana $\mathrm{f}(\mathrm{we})$ merupakan water influx. Dengan menyusun kembali Persamaan Material Balance yaitu

$$
G+\frac{W e+W p B w}{B g-B g i}=\frac{G p B g}{B g-B g i}
$$

Dimana We (Water influx) dapat dicari dengan persamaan yaitu :

$$
W e=G p B g-G(B g-B g i)
$$




\section{Metode P/z vs Gp}

Metode Cole Plot merupakan metode untuk melihat perilaku reservoir dengan melakukan Plot $\mathrm{Gp} . \mathrm{Bg} /(\mathrm{Bg}$ Bgi) terhadap Gp untuk melihat indikasi water influx dan driving mechanism serta pembeda antara water drive dan depletion drive .metode cole ini adalah metode plot yang berasal dari persamaan material balance secara umum yaitu :

$$
F=G \cdot E t+W e
$$

Dimana $\mathrm{F}$ adalah kumulatif reservoir voidge

$$
F=G p \cdot B g+W p \cdot B w
$$

Et adalah kumulaif ekspansi Total :

$$
E t=E g=B g-B g i
$$

Setelah persamaan $\mathrm{F}=\mathrm{G} . \mathrm{Et}+\mathrm{We}$ disubtitusikan dengan persamaan $\mathrm{F}=\mathrm{Gp} \cdot \mathrm{Bg}+\mathrm{Wp} \cdot \mathrm{Bw}$ maka didapatkan persamaan sebagai berikut :

$$
\frac{\mathrm{Gp} \cdot \mathrm{Bg}}{\mathrm{Bg}-\mathrm{Bgi}}=\mathrm{G}+\frac{\mathrm{We}-\mathrm{Wp} \cdot \mathrm{Bw}}{\mathrm{Bg}-\mathrm{Bgi}}
$$

Jika reservoir gas tersebut berjenis depletion drive, maka grafik hasil plot akan berbentuk horizontal, dengan $\mathrm{Y}$-axis = OGIP. Namun, jika reservoir gas tersebut berjenis water drive maka plot tidak akan berbentuk horizontal dan akan memiliki kemiringan (slope), yang berbeda-beda antara strong water drive, moderate water drive dan weak water drive.

\section{Simulator IPM 7.5 Petroleum Expert}

\section{Mbal 10.5}

MBAL adalah seperangkat alat untuk menganalisan reservoir yang menggunakan data sejarah produksi reservoir dan data PVT dari fluida yang diproduksikan untuk memperkirakan Stock Tank Original Gas In Place (STOGIP) dengan memperhitungkan keseimbangan massa, serta mengidentifikasi mekanisme pendorong reservoir. Data PVT serta sejarah produksi yang lengkap dan baik untuk dimasukkan ke dalam MBAL sebagai data Input.

\section{Prosper 11.5}

PROSPER adalah seperangkat program yang digunakan untuk membuat model sumur, guna menganalisa dari aspek PVT (karakteristik fluida), korelasi yang digunakan untuk menghitung pressure loss di tubing dan merupakan perhitungan terhadap vertical lift performance, serta dapat menentukan kurva IPR.

\section{HASIL DAN PEMBAHASAN}

Struktur Musi Barat Lapangan Riyadh berdasarkan data PT.Pertamina EP Prabumulih bahwa diperkirakan cadangan gas berdasarkan volumetric dengan menggunakan alat planimeter yaitu IGIP (Initial Gas in Place ) P1 686,334.983 MMCF.

\section{Perkiraan Cadangan Gas Dengan Metode P/z vs Gp}

Metode $\mathrm{P} / \mathrm{z}$ vs $\mathrm{Gp}$ adalah metode memperkirakan cadangan dengan mengabaikan $\mathrm{We}=0$. Adapun parameter yang berpengaruh terhadap perkiraan cadangan ini adalah $\mathrm{Z}$ faktor.berikut tabel hasil $\mathrm{P} / \mathrm{z}$ terhadap kumulatif produksi gas 
Tabel 1. Hasil Perhitungan P/z vs Gp

\begin{tabular}{ccc}
\hline Tanggal & Gp(Bcf) & $\mathbf{p} / \mathbf{z}(\mathbf{P s i})$ \\
\hline Dec-95 & 0.00 & 1637.19 \\
\hline Dec-05 & 10.81 & 1598.95 \\
\hline Dec-06 & 26.50 & 1545.06 \\
\hline Dec-07 & 59.07 & 1439.10 \\
\hline Dec-08 & 99.97 & 1316.52 \\
\hline Feb-09 & 110.9973 & 1285.35 \\
\hline Mar-09 & 117.1504 & 1268.27 \\
\hline Dec-09 & 170.9428 & 1128.82 \\
\hline Mar-10 & 188.1634 & 1087.64 \\
\hline May-10 & 199.2989 & 1061.85 \\
\hline Dec-10 & 236.5725 & 980.05 \\
\hline Dec-11 & 289.4469 & 875.15 \\
\hline Dec-16 & 505.33 & 554.42 \\
\hline
\end{tabular}

Pada tabel diatas maka dapat dilakukan plot P/z terhadap kumulatif gas.berikut grafik P/z vs Gp :

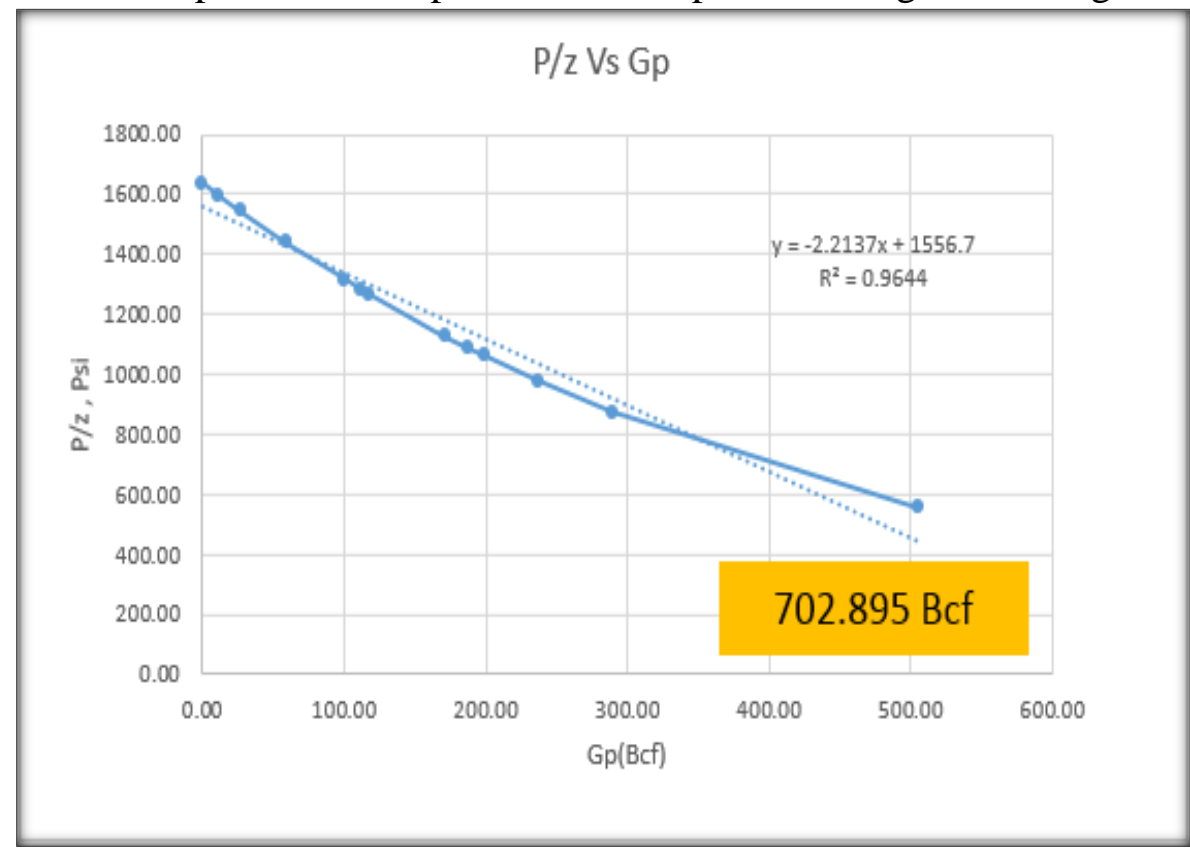

Grafik 1. Hasil Plot P/z vs Gp

Hasil perkiraan cadangan dapat diketahui berdasarkan persamaan pada trendline yaitu $\mathrm{y}=-2.2137 \mathrm{x}$ +1556.9 maka dengan persamaan ini dapat diperkirakan cadangan gas pada lapangan Riyadh

$$
\begin{aligned}
I G I P & =\frac{1556.9}{2.2137} \\
& =702.895 B c f
\end{aligned}
$$




\section{Identifikasi Driving Mechanism Lapangan Riyadh}

Untuk mengetahui driving mechanism pada lapangan Riyadh dapat dilakukan dengan analisa pada plot P/z vs Gp dan metode cole plot berdasarkan teori pada (Beggs, Dale H; "Gas Production Operations"1984). Perlu dikethui jika terjadi perembesan air (reservoir water drive), volume hidrokarbon reservoir tidak konstan terhadap waktu sebagai akibat plot $\mathrm{P} / \mathrm{z}$ versus Gp tidak berupa garis lurus. Hasil plot kurva suatu reservoir water drive, biasanya cekung (terbuka) ke atas. Karena adanya water influx, maka penurunan tekanan bersama produksi tidak begitu cepat daripada di bawah pengaruh volumetris (depletion drive).berikut hasil dari Plot P/z vs Gp lapangan Riyadh dengan hasil garis tidak berupa garis Lurus

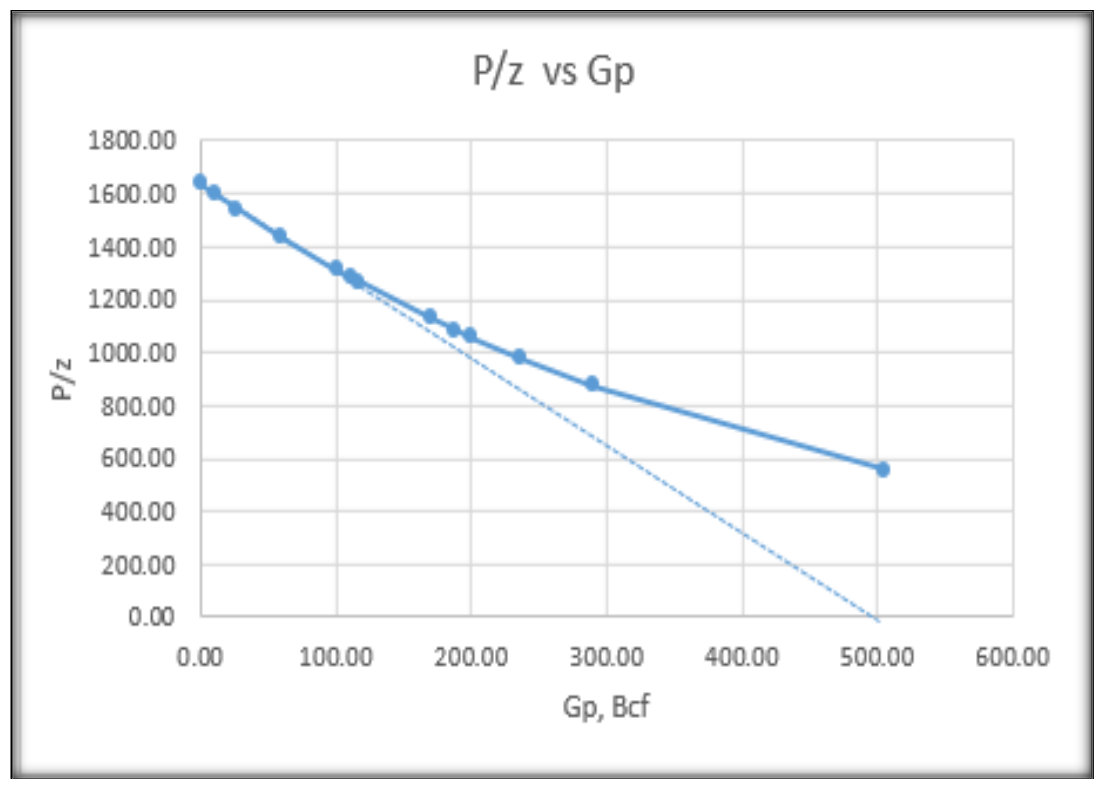

Grafik 2 Hasil Plot P/Z vs Gp Indikasi Water Influx

Jadi dapat dilihat pola bahwa pada grafik di atas menunjukkan adanya efek dari water influx sebagai reservoir water drive.

Kemudian indikasi yang menyatakan bahwa reservoir lapangan Riyadh ini merupakan reservoir dengan driving mechanism Strong water drive dapat dilakukan dengan analisa Cole plot yaitu Cole mengusulkan untuk melakukan plot $\mathrm{Gp} . \mathrm{Bg} / \mathrm{Bg}$-Bgi pada Y-axis dan kumulatif produksi X gas (Gp) . Nilai faktor volume formasi gas dihitung mengunakan persamaan:

Keterangan :

$$
B g=0,02829 Z . T r / P r, \text { Cuft/Scf }
$$

$$
\begin{array}{ll}
\mathrm{Bg} & =\text { Faktor volume formasi gas, Cuft } / \mathrm{scf} \\
\mathrm{Z} & =\text { Faktor deviasi gas } \\
\mathrm{Tr} & =\text { Temperature } \text { Reservoir, }{ }^{\circ} R \\
\mathrm{Pr} & =\text { Pressure } \text { Reservoir, Psi }
\end{array}
$$

Jika reservoir gas tersebut berjenis water drive maka plot tidak akan berbentuk horisontal dan akan memiliki kemiringan (slope), yang berbeda-beda antara strong water drive, moderate water drive dan weak water drive. Berikut hasil Cole Plot untuk reservoir pada lapangan riyadh : 


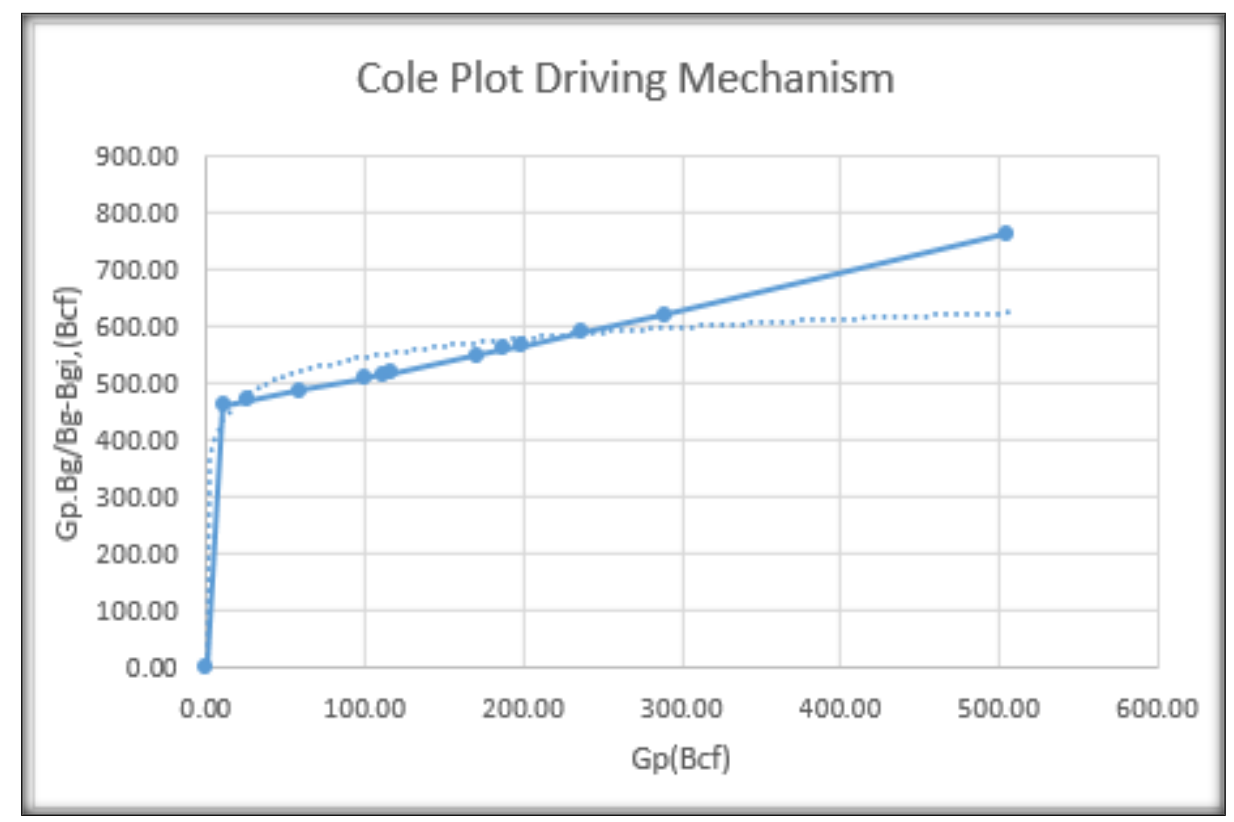

Grafik 3 Hasil Cole Plot Reservoir Lapangan Riyadh

Pada grafik 3 dapat dilihat dengan membandingkan dengan teori cole plot bahwa driving mechanism reservoir Lapangan Riyadh yaitu Strong water drive. Hasil Plot pada gambar 3 dapat dilihat pada tabel dibawah ini :

Tabel 2. Hasil Cole Plot Lapangan Riyadh

\begin{tabular}{ccc}
\hline $\mathbf{G p}(\mathbf{B c f})$ & Bg $(\mathbf{c u f t} / \mathbf{s c f})$ & GpBg/Bg-Bgi \\
\hline $\mathbf{0 . 0 0}$ & 0.01071 & 0.00 \\
\hline $\mathbf{1 0 . 8 1}$ & 0.01096 & 462.73 \\
$\mathbf{2 6 . 5 0}$ & 0.01134 & 470.85 \\
$\mathbf{5 9 . 0 7}$ & 0.01218 & 488.17 \\
\hline $\mathbf{9 9 . 9 7}$ & 0.01331 & 510.40 \\
\hline $\mathbf{1 1 1 . 0 0}$ & 0.01364 & 516.49 \\
\hline $\mathbf{1 1 7 . 1 5}$ & 0.01382 & 519.88 \\
\hline $\mathbf{1 7 0 . 9 4}$ & 0.01553 & 550.52 \\
\hline $\mathbf{1 8 8 . 1 6}$ & 0.01612 & 560.56 \\
\hline $\mathbf{1 9 9 . 3 0}$ & 0.01651 & 567.12 \\
\hline $\mathbf{2 3 6 . 5 7}$ & 0.01788 & 589.39 \\
\hline $\mathbf{2 8 9 . 4 5}$ & 0.02003 & 621.85 \\
\hline $\mathbf{5 0 5 . 3 3}$ & 0.03161 & 764.08 \\
\hline & &
\end{tabular}




\section{Optimasi Recovery Perolehan Gas dengan Simulator IPM 7.5}

Lapangan Riyadh terdiri dari 20 sumur produksi gas berdasarkan well diagram ukuran tubing yang digunakan yaitu tubing 3 inch oleh karena itu dilakukan tahap optimasi recovery perolehan gas berdasarkan parameter design sumur.

Kemudian telah diketahui bahwa perkiraan cadangan pada lapangan Riyadh yaitu 702895 MMcf. Dapat diperkirakan RF prediksi pada lapangan riyadh dengan persamaan kesetimbangan materi. Berikut hasil tabel dibawah ini :

Tabel 3. Hasil Perkiraan Cadangan Lapangan Riyadh

\begin{tabular}{ccccccc}
\hline Tahun & $\begin{array}{c}\text { IGIP } \\
\text { (Bcf) }\end{array}$ & $\begin{array}{c}\text { Gp } \\
\text { (Bcf) }\end{array}$ & $\begin{array}{c}\text { RF } \\
\text { current } \\
\text { \% }\end{array}$ & $\begin{array}{c}\text { RF } \\
\text { prediksi } \\
\text { \% }\end{array}$ & $\begin{array}{c}\text { EUR } \\
\text { (Bcf) }\end{array}$ & $\begin{array}{c}\text { Remaining } \\
\text { (Bcf) }\end{array}$ \\
\hline $\mathbf{2 0 1 6}$ & 702.895 & 505.33 & $72 \%$ & $82 \%$ & 574.718 & 63.388 \\
\hline
\end{tabular}

Untuk mendapatkan Bga dapat ditentukan dari grafik Bg terhadap tekanan reservoir. Tekanan abandon ditetapkan yaitu 20 Psi berdasarkan ketentuan Exploitation PT.Pertamina EP karena yang diharapkan tekanan abandon sekecil mungkin sehingga produksi gas dapat diperoleh sebanyak mungkin.berikut cara untuk mendapatkan Bga (Faktor volume formasi gas abandon).

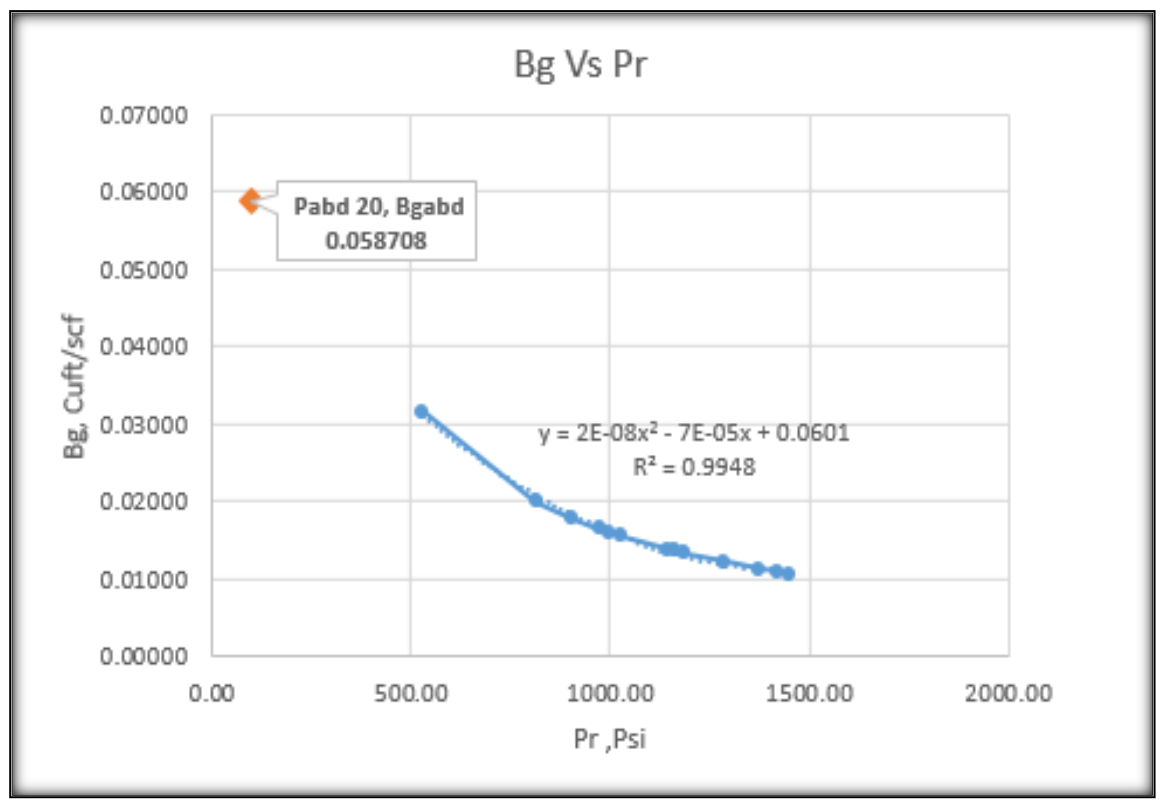

Grafik 4. Faktor Volume Formasi Gas Abandon

Pada grafik di atas maka didapatkan persamaan yaitu $\mathrm{y}=2 \mathrm{E}-08 \mathrm{x}^{2}-7 \mathrm{E}-05 \mathrm{x}+0.0601$. variable $\mathrm{x}$ adalah tekanan abandon yaitu pada tekanan abandon 20 psi.

$$
\begin{aligned}
B g a & =2 E-0.8 \times 20^{2}-7 E-05 \times 20+0.0601 \\
& =0.05870 \mathrm{cuft} / \mathrm{scf}
\end{aligned}
$$

Jadi dapat disimpulkan bahwa lapangan Riyadh dapat diperkirakan memiliki potensi perolehan gas hingga $82 \%$ dengan perkiraan recoverable yaitu 574.718 sehingga dari RF current $72 \%$ dapat diperkirakan perolehan gas sebesar 69.39 Bcf. Perkiraan ini masih dalam perhitungan tanpa efek dari parameter design sumur yang akan dilakukan dalam simulasi Mbal. 


\section{Prosper}

Pada bagian prosper akan ditentukan sensivity 3 variable system yaitu variable condensate gas rasio, water gas rasio dan pressure tujuannya yaitu untuk data tubing performance curve.

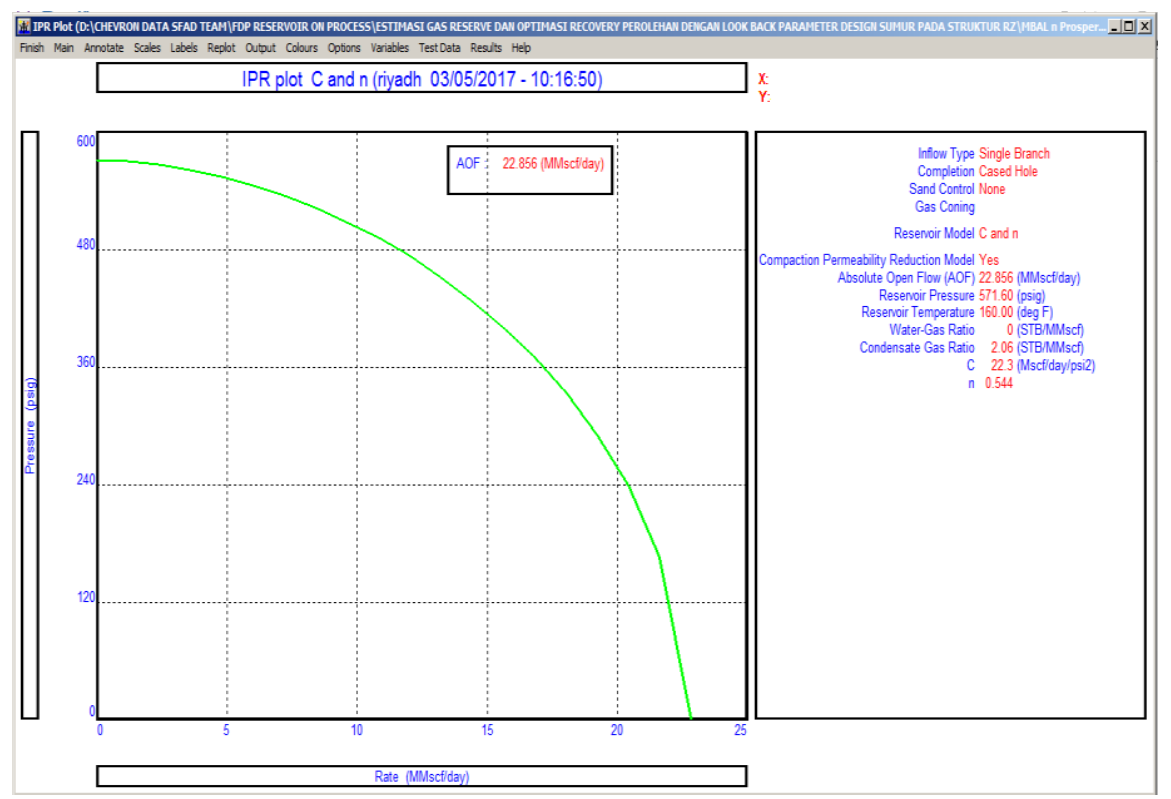

\section{Mbal}

Grafik 5. Hasil Absolut Open Flow Sumur RJ-01

Dari hasil run simulation dapat dilakukan plot untuk melihat data history dan data hasil simulasi . berikut hasil history matching pada tekanan terhadap waktu :

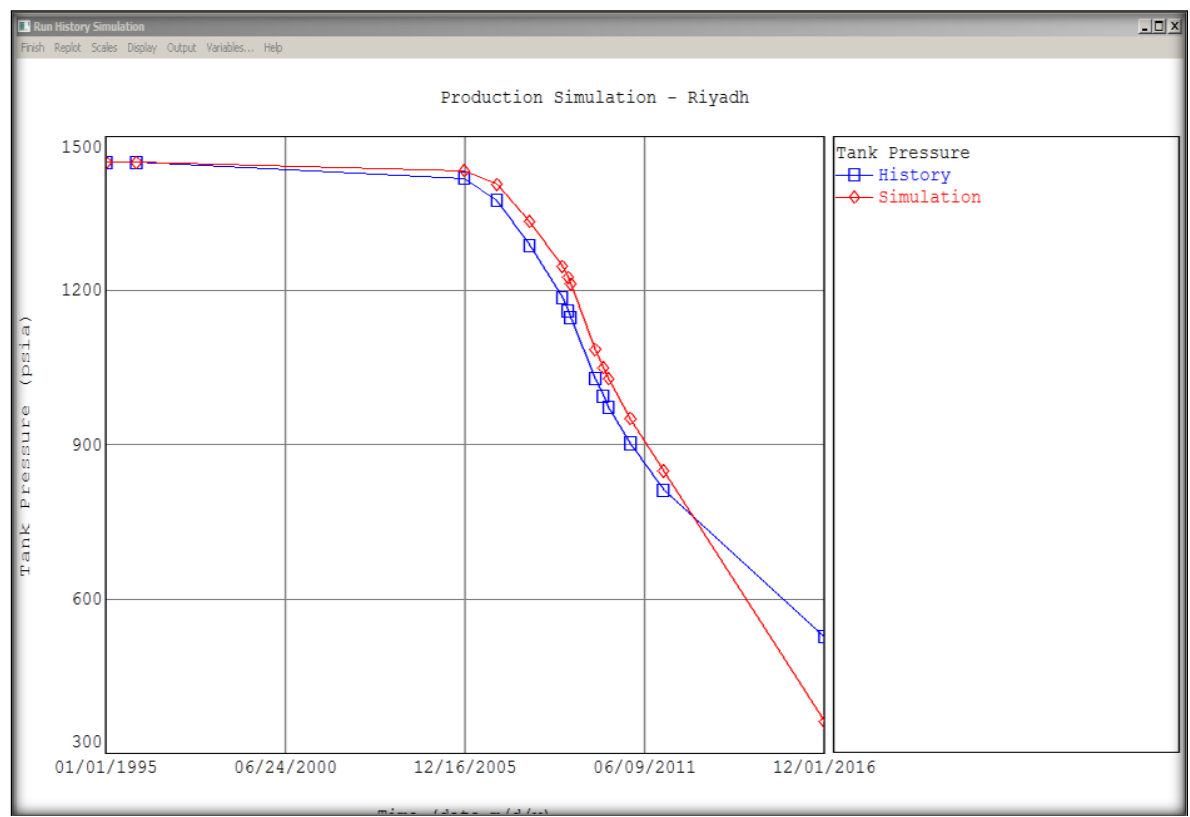

Grafik 6. History Matching Lapangan Riyadh

Dapat disimpulakan bahwa perbandingan data history terhadap simulasi dikategorikan matching dengan \% error sebesar $1.32 \%$. kemudian dapat dilihat hasil grafik model tank reservoir sehingga dapat dilakukan deskripsi terhadap reservoir lapangan riyadh sebagai berikut : 


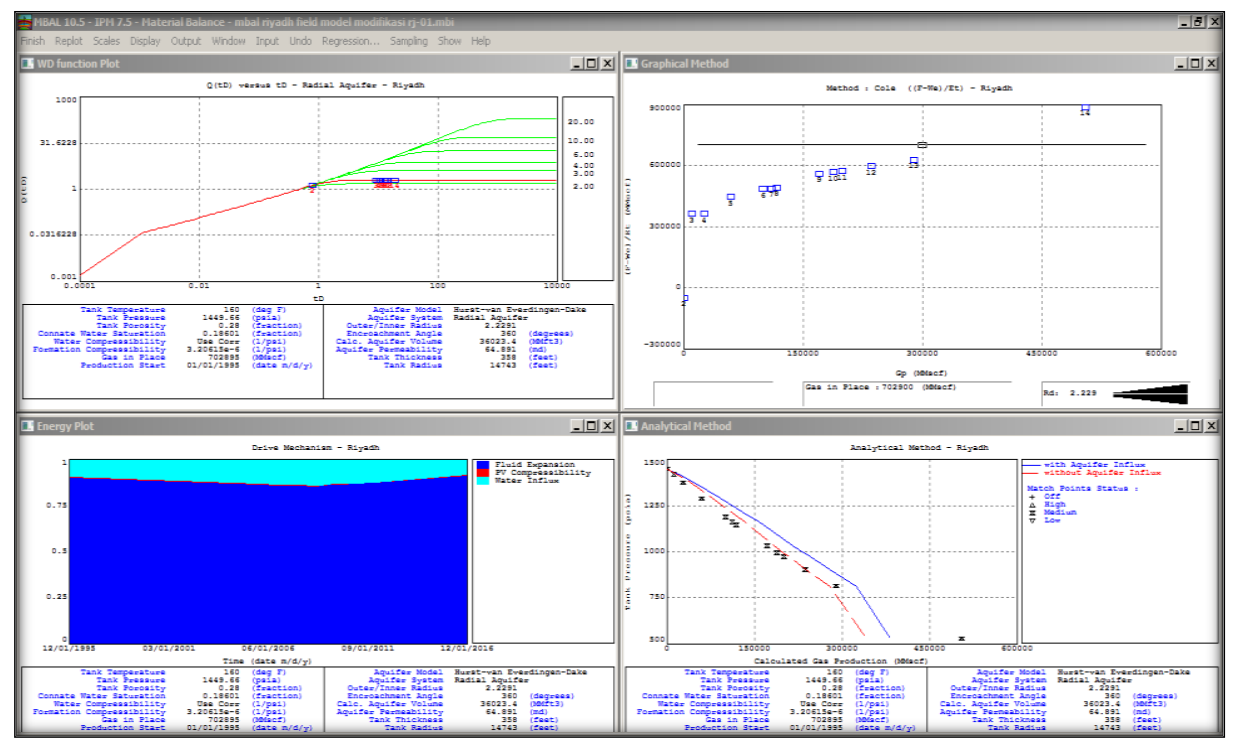

Grafik 7. Deskripsi Reservoir Lapangan Riyadh

\section{KESIMPULAN}

1. Dari Hasil perhitungan cadangan gas dengan metode Material Balance P/z vs Gp didapatkan hasil perkiraan cadangan gas sebesar $702.895 \mathrm{Bcf}$

2. Berdasarkan analisa dari metode $\mathrm{P} / \mathrm{z}$ vs Gp dapat dilihat bahwa reservoir gas pada struktur musi barat Lapangan Riyadh dipengaruhi oleh aquifer influx sehingga dari hasil Cole Plot di Identifikasi bahwa driving mechanism reservoir gas di Struktur Musi Barat Lapangan Riyadh adalah Strong Water Drive

3. Kemudian pada hasil prediksi bahwa perkiraan recovery perolehan gas secara manual yaitu $82 \%$ tanpa efek parameter design sumur yaitu tubing dan dilakukan optimasi recovery perolehan gas dengan simulasi Mbal didapatkan hasil recovery perolehan yaitu $85 \% 601993$ MMscf sampai tahun 2028.maka dapat diartikan dari RF current $72 \%$ dapat dioptimasikan hingga RF $85 \%$.dan dengan tubing 3 inch sudah optimum untuk mencapai recovery perolehan gas tanpa ada setiap sumur yang terjadi kehilangan produksi dipertengahan tahun.

\section{DAFTAR PUSTAKA}

Ahmed, Tarek, 2000, "Reservoir Engineering Handbook", Gulf Publishing Company, Houston, Texas.

Beggs, Dale. H. 1984, ”Gas Production Operation”,

Chi U.Ikoku, 1992, “Natural Gas Reservoir Engineering”, Krieger Publishing Company, Malabar. Flourida.

Craft, B. C. and Hawkins, 1959, M. F.: “Applied Petroleum Reservoir Engineering”, NJ, USA.: pp 70-71. Prentice Hall.

Dake, L.P., 1978, "Fundamentals of Reservoir Engineering", Elsevier Scientific Publishing Company, Amsterdam-Oxford-New York.

Emil, Burchik J, 1983, "Properties of Petroleum Reservoir Engineering”, Professore emirtus of petroleum and Natural Gas Engineering The Pennsylvenia State University. 
John Lee W., Wattenbarger Robert A., 1996, "Gas Reservoir Engineering”, Society of Petroleum Engineer.

Jr, Mc. Cain, William D., 1999 “The Properties of Petroleum Fluids 2nd Ed.”, Pennwell Books, Tulsa, Oklahoma, United States.

P.M Dranchuk-J.H.Abou Kassem:" Calculation of Z factor for Natural Gases Using Equation of State", JCPT73-03-03

Sutton, R.P, 1985, "Compressibility Factor for High-Molecular-Weight Reservoir Gases", SPE Annual Technical Conference and Exhibition, Las Vegas, Nevada, USA. 